\title{
Health and Disability
}

\section{Work-related stress and well-being: The roles of direct action coping and palliative coping}

\author{
LINA FORTES-FERREIRA, JOSÉ M. PEIRÓ, M. GLORIA GONZÁLEZ-MORALES and ISABEL MARTÍN \\ University of Valencia, Spain
}

Fortes-Ferreira, L., Peiró, J. M., González-Morales, M. G. \& Martín, I. (2006). Work-related stress and well-being: The roles of direct action coping and palliative coping. Scandinavian Journal of Psychology, 47, 293-302

The purpose of the present study is to analyze the roles of direct action coping and palliative coping in the relationship between work stressors and psychological well-being, as well as their possible interactions, in a sample of 464 bank employees. Hierarchical regression analyses showed main effects of direct action coping on well-being. Palliative coping predicts higher levels of psychological distress. Contrary to what was expected, the interactions between work stressors and direct action coping were not significant. Palliative coping interacted with work stressors when predicting psychosomatic complaints. The interaction between the two types of coping was significant on psychosomatic complaints and psychological distress, but not on job satisfaction. The paper discusses theoretical and practical implications of these results, in order to design intervention strategies to prevent and manage job stress.

Key words: Work stress, direct action coping, palliative coping, interaction between coping strategies, well-being.

Jose M. Peiró, Departamento de Psicología Social, Facultad de Psicología, Av. Blasco Ibáñez, 21, 46010 Valencia, Spain. E-mail: Jose.M.Peiro@uv.es 